This is a self-archived version of an original article. This version may differ from the original in pagination and typographic details.

Author(s): Wang, Li-Li; Tu, Yi-Kuan; Valkonen, Arto; Rissanen, Kari; Jiang, Wei

Title: Selective Recognition of Phenazine by 2,6-DibutoxyInaphthalene-Based Tetralactam Macrocycle

Year: 2019

Version: Accepted version (Final draft)

Copyright: @ 2019 SIOC, CAS \& WILEY-VCH Verlag GmbH \& Co. KGaA

Rights: In Copyright

Rights url: http://rightsstatements.org/page/InC/1.0/?language=en

Please cite the original version:

Wang, L., Tu, Y., Valkonen, A., Rissanen, K., \& Jiang, W. (2019). Selective Recognition of Phenazine by 2,6-Dibutoxylnaphthalene-Based Tetralactam Macrocycle. Chinese Journal of Chemistry, 37(9), 892-896. https://doi.org/10.1002/cjoc.201900233 


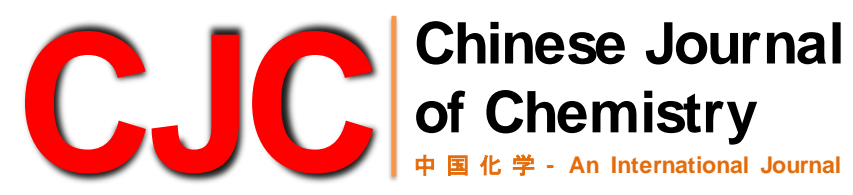

\section{Accepted Article}

Title: Selective Recognition of Phenazine by 2,6-Dibutoxylnaphthalene-Based Tetralactam Macrocycle

Authors: Li-Li Wang, Yi-Kuan Tu, Arto Valkonen, Kari Rissanen, and Wei Jiang*

This manuscript has been accepted and appears as an Accepted Article online.

This work may now be cited as: Chin. J. Chem. 2019, 37, 10.1002/cjoc.201900233.

The final Version of Record (VoR) of it with formal page numbers will soon be published online in Early View: http://dx.doi.org/10.1002/cjoc.201900233. 


\title{
Selective Recognition of Phenazine by 2,6-Dibutoxylnaphthalene-Based Tetralactam Macrocycle
}

\author{
Li-Li Wang, ${ }^{a}$ Yi-Kuan Tu, ${ }^{a}$ Arto Valkonen, ${ }^{\mathrm{b}}$ Kari Rissanen, ${ }^{\mathrm{b}}$ and Wei Jiang*,a \\ ${ }^{a}$ Shenzhen Grubbs Institute and Department of Chemistry, Southern University of Science and Technology, Xueyuan Blvd 1088, Shenzhen 518055, China \\ ${ }^{b}$ Department of Chemistry, Nanoscience Center, University of Jyvaskyla, P. O. Box 35, Jyväskylä 40014, Finland
}

Cite this paper: Chin. J. Chem. 2019, 37, XXX-XXX. DOI: 10.1002/cjoc.201900XXX

Summary of main observation and conclusion A 2,6-dibutoxylnaphthalene-based tetralactam macrocycle was designed and synthesized. This macrocycle shows highly selective recognition to phenazine -- a well-known secondary metabolite in bacteria and an emerging disinfection byproduct in drinking water. In contrast, the macrocycle shows no binding to the structurally similar dibenzo-1,4-dioxin. It was revealed that hydrogen bonding, $\pi-\pi$ and $\sigma-\pi$ interactions are the major driving forces between phenazine and the new tetralactam macrocycle. A perfect complementarity in electrostatic potential surfaces may explain the high selectivity. In addition, the macrocycle shows fluorescent response to phenazine, demonstrating its potential in fluorescent detection of phenazine.

\section{Background and Originality Content}

Phenazine, an N-heterocyclic polyaromatic hydrocarbon, widely exists in biology and environment. Phenazine and its derivatives are well-known secondary metabolites in many bacteria. ${ }^{[1]}$ Phenazine is also a common dye and is used in chemical sensing, ${ }^{[2]}$ optoelectronic materials ${ }^{[3]}$ and other fields. ${ }^{[4]}$ Recently, phenazine was identified as a disinfection byproduct in drinking water. ${ }^{[5]}$ The toxicity of phenazine to human has been investigated and the latest research reveals phenazine to have a minor cytotoxic antiproliferative effect but significant genotoxicity to human. ${ }^{[6,7]}$ Due to the wide distribution in environment, selective recognition of phenazine is crucial for its sensing and remediation. As shown in Figure 1a, phenazine contains two (1) hydrogen bonding acceptor nitrogen atoms and is structurally planar. A good synthetic receptor should be complementary to the electrostatic potential surface of phenazine in its cavity. Tetralactam macrocycles with four inward-directed amide $\mathrm{NHS}$ would be an ideal receptor for phenazine. ${ }^{[3]}$

Over the last decades, several tetralactam macrocycles have been reported as synthetic receptors, ${ }^{[8-12]}$ which were applied in various fields, including chemical sensing, [13 ] molecular machines, ${ }^{[14,15]}$ fluorescent imaging, ${ }^{[16]}$ organocatalysis ${ }^{[17]}$ and separations. ${ }^{[18]}$ They show high affinity to guests containing hydrogen bonding acceptors. ${ }^{[19]}$ The known tetralactam macrocycles could be divided into three categories according to the type of their sidewalls: angular arene, planar arenes, and aliphatic sidewalls (Figure $1 \mathrm{~b}$ ). When compared to tetralactam macrocycles with angular arene and aliphatic sidewalls, the ones with planar arene sidewall should be more structurally complementary to planar phenazine. Additional $\pi \cdots \pi$ or $\sigma \cdots \pi$ interactions may be involved between the planar sidewalls and phenazine besides hydrogen bonding. The planar aromatic sidewalls of tetralactam macrocycles are currently limited to benzene, anthracene and their derivatives. Phenyl sidewalls are too narrow to interact with phenazine. In addition, anthracene and phenazine are both electron-rich and it may not be favorable for them to have attractive $\pi \cdots \pi$ interactions. ${ }^{[20,21]}$ Although the tetralactam macrocycle with anthracene as sidewalls was reported to be able to encapsulate phenazine in solid state, the solution complexation was not studied. ${ }^{[3]}$ Naphthalene may be a good compromise as sidewalls to maximize $\sigma \cdots \pi$ interactions with phenazine. However, tetralactam macrocycles with naphthalene as sidewalls were rarely studied. ${ }^{[22]}$

During the last six years, we reported a series of naphthol-based macrocyclic receptors which have been used in molecular recognition, ${ }^{[23,24,25]}$ molecular sensing, ${ }^{[26-29]}$ molecular machine, ${ }^{[30]}$ cooperative self-assembly ${ }^{[31]}$ and supramolecular hydrogel. ${ }^{[32]}$ We recently synthesized a tetralactam macrocycle with 2,3-dibutoxylnaphthalene. ${ }^{[22]}$ In this article, we report the synthesis and characterization of 2,6-dibutoxylnaphthalene-based tetralactam macrocycle (TM1) and its selective recognition to phenazine in nonpolar solvent. The macrocycle shows rather high binding selectivity to phenazine and show no binding at all to structurally similar dibenzo-1,4-dioxin.

*E-mail: Wei Jiang - jiangw@sustech.edu.cn

This article has been accepted for publication and undergone full peer review but has not been through the copyediting, typesetting, pagination and proofreading process, which may lead to differences between this version and the Version of Record. Please cite this article as doi: $10.1002 /$ cjoc. 201900233 
(a)

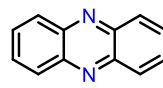

phenazine

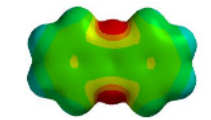

electrostatic potential surface (b)

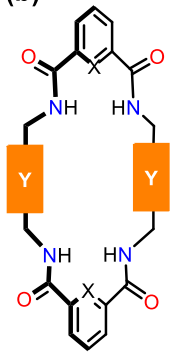

$\mathrm{X}=\mathrm{CH}$ or $\mathrm{N}$
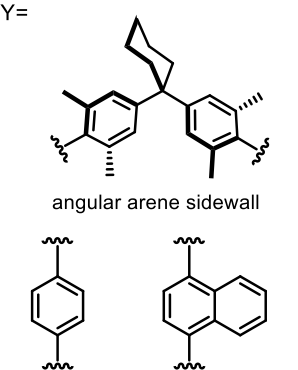

angular arene sidewall

phatic sidewall

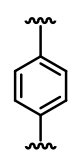

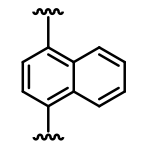

plane arene sidewall
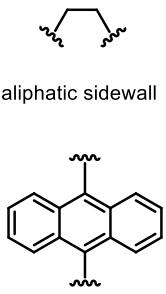

igure 1 (a) Chemical structure and electrostatic potential surface of

- phenazine, and (b) representatives of the known tetralactam macrocycles.

13

(a) $\mathrm{BuO}$
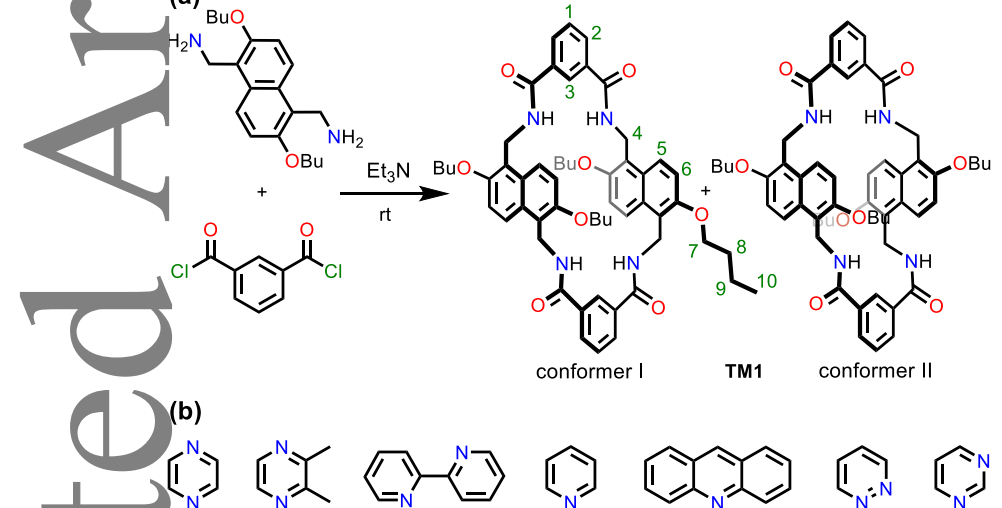

年年

$\mathrm{OBu}$
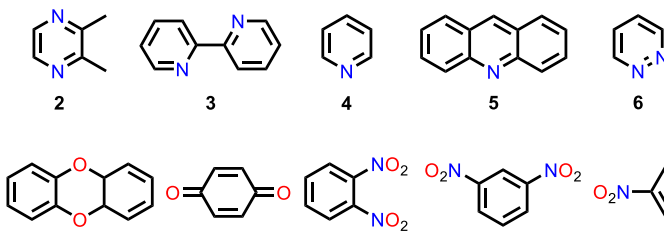

5
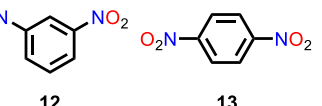

10

11

Scheme 1 (a) Synthetic route of tetralactam macrocycle TM1; (b) chemical tructures of neutral guests 1-13

\section{Results and Discussion}

Synthetic route of macrocycle TM1 is shown in Scheme 1. The diamine and isophthaloyl dichloride react under a pseudo-high dilution condition in the presence of $\mathrm{Et}_{3} \mathrm{~N}$ at room temperature, affording tetralactam macrocycle TM1 with a yield of $20 \%$. Electrospray ionization (ESI) mass spectra support the isolated product to be the [2+2] macrocycle TM1 (see Supporting Information).

There are two conformations for TM1 because of the flipping of the two 2,6-dibutoxylnaphthalenes (Scheme 1). These two conformations should give the same number of peaks with different chemical shifts in the NMR spectrum. If they coexist, two sets of NMR signals should be expected. However, only one set of

signals are observed in the ${ }^{1} \mathrm{H}$ NMR spectrum of TM1 (Figure 2a), suggesting that either only one conformation is predominant in the solution or the conformational interconversion is fast at the NMR timescale. When lowering the temperature to $223 \mathrm{~K}$ (Figure 2), the NMR peaks were split into two sets, supporting the existence of two different conformers.

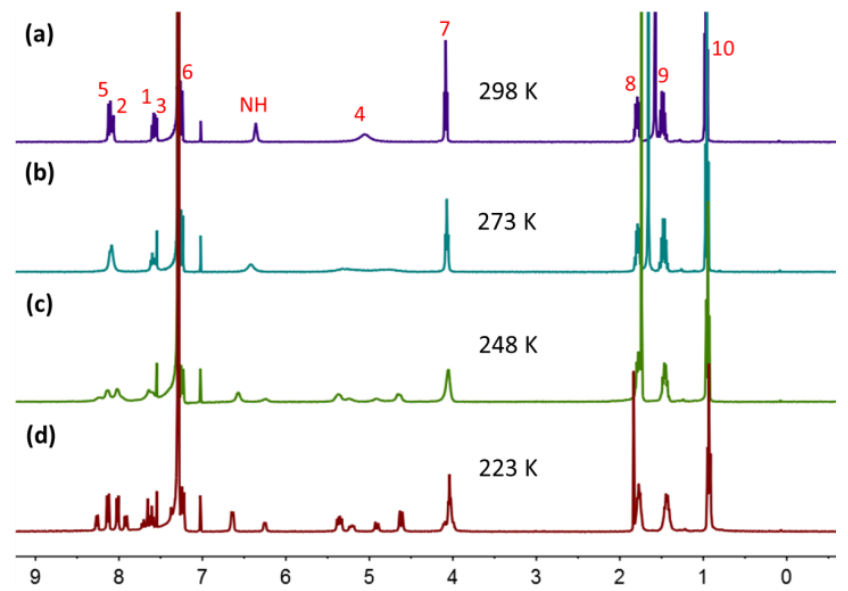

Figure $2{ }^{1} \mathrm{H}$ NMR spectra (400 MHz, $\mathrm{CDCl}_{3}$ ) of TM1 at (a) $298 \mathrm{~K}$, (b) $273 \mathrm{~K}$, (c) $248 \mathrm{~K}$ and (d) $223 \mathrm{~K}$.

Single crystal of TM1, which is suitable for X-ray crystallography, was obtained by slow evaporation of its solution in acetone. The crystal structure (Figure 3 ) clearly shows that TM1 adopts a chair conformation with the two 2,6-dibutoxylnaphthalenes in a parallel orientation. The structure contains four water molecules, two of which and two solvent acetone molecules are trapped in the cavity. All the four amide $\mathrm{NH}$ residues are directed into the cavity. Isophthalamide $\mathrm{NH}$ protons and the phenyl $\mathrm{CH}$ protons are hydrogen-bonded to the oxygen atoms of the cavity water molecules (for $\mathrm{N}-\mathrm{H} \cdots \mathrm{O}: \mathrm{H} \cdots \mathrm{O}$

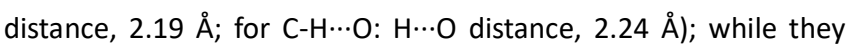
are further hydrogen-bonded to the acetone molecules through $\mathrm{O}-\mathrm{H} \cdots \mathrm{O}(\mathrm{H} \cdots \mathrm{O}$ distance, $2.06 \AA)$ and $\mathrm{O} \cdots \mathrm{H}-\mathrm{C}_{\text {acetone }}(\mathrm{O} \cdots \mathrm{H}$ distance, $2.64 \AA$ ) hydrogen bonds. The two other water molecules connect the adjacent TM1 macrocycles through $\mathrm{H}-\mathrm{O}-\mathrm{H} \cdots \mathrm{O}=\mathrm{C}$ hydrogen bonds $(\mathrm{H} \cdots \mathrm{O}=\mathrm{C}$ distance, ca. $1.92 \AA)$. In addition, there is a hydrogen bond to the cavity water molecule of yet an another adjacent TM1 macrocycle $\left(\mathrm{OH} \cdots \mathrm{OH}_{2}\right.$ distance, $\left.1.86 \AA\right)$. The two acetone molecules are aligned in a line and threaded through the cavity defined by the two 2,6-dibutoxylnaphthalenes. This crystal structure suggests macrocycle TM1 should be a good host for the guests with complementary shape and hydrogen-bonding acceptors. 

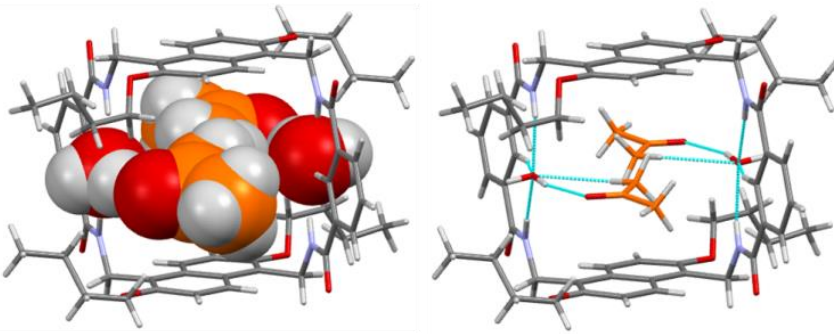

Figure 3 X-ray single crystal structure of TM1 obtained from its acetone solution.

Macrocycle TM1 is indeed a receptor for phenazine. In the ${ }^{1} \mathrm{H}$ NMR spectrum of the equimolar mixture of TM1 and phenazine, significant upfield shifts were observed for the naphthalene protons of the host and the aromatic protons of the guest when compared to the ${ }^{1} \mathrm{H}$ NMR spectra of their free states (Figure 4). This suggests that phenazine should be encapsulated in the cavity of TM1 and the naphthalenes and the phenazine are mutually located in the shielding region of each other. Meanwhile, the amide NH protons shift downfield, suggesting hydrogen bonding between the amide protons and the guest exists. This further supports that phenazine should be encapsulated in the cavity of TM1. The broadened signals may be caused by the intermediate exchange rate of the host-guest complex at the NMR timescale. Job's plot supports a 1:1 binding stoichiometry (Figures S1 and S2).

Table 1 Association constants $K_{\mathrm{a}}\left(\mathrm{M}^{-1}\right)$ of TM1 to the guests as determined by ${ }^{1} \mathrm{H}$ NMR titrations.

\begin{tabular}{ccccc}
\hline phenazine & $\mathbf{1}$ & $\mathbf{2}$ & $\mathbf{3}$ & $\mathbf{8}$ \\
\hline 780 & 24 & 130 & 68 & 6.9 \\
\hline
\end{tabular}

Macrocycle TM1 is highly selective to phenazine among other similar compounds. Thirteen additional guests were selected for comparison. All these guests contain nitrogen or oxygen atoms as hydrogen bonding acceptors. Since binding in the cavity of TM1 would cause obvious upfield shift of the guest signals, simple ${ }^{1} \mathrm{H}$ NMR experiments of their 1:1 mixtures were performed to evaluate the binding (Figures S3 - S15). Compounds 1 - 3 and 8 are proven to be guests for TM1. No obvious binding was detected for other guests. The binding constants of phenazine, guests $\mathbf{1}-\mathbf{3}$ and $\mathbf{8}$ were determined by ${ }^{1} \mathrm{H}$ NMR titrations (Figures S16 - S25) and are listed in Table 1. In general, these guests show much weaker binding affinity than phenazine $\left(780 \mathrm{M}^{-1}\right)$. The binding constant of TM1 to phenazine was also confirmed by UV-Vis titration (Figures S26 and S27).

Guests 1 - 3 contain two nitrogen atoms which are positioned in an appropriate distance to satisfy the hydrogen bonding of two isophthalamides. In contrast, guests $4-7$, which contain either one nitrogen atom or two nitrogen atoms that are not well positioned for hydrogen bonding with the two isophthalamides of the hosts, are not guests for TM1 Consequently, hydrogen bonding is very crucial for the binding of TM1. Surprisingly, guests $\mathbf{8}$ - $\mathbf{1 3}$ with oxygen atoms as hydrogen bonding acceptors all show very poor binding to TM1. Only guest 8 gives rise to a binding constant of $6.9 \mathrm{M}^{-1}$; while the other five guests do not show obvious binding at all. This is in great contrast to the urea/thioureal naphthotubes which can effectively bind these guests. ${ }^{[23]}$ Most surprisingly, dibenzo-1,4-dioxin 9, which is structurally very similar to phenazine and contains two oxygen instead of nitrogen atoms, is not a guest to TM1. This is even expressed in a control experiment with equimolar mixture of TM1, phenazine, and 9 (Figure S28). That is, TM1 is a very selective receptor to phenzine over other structurally similar compounds.

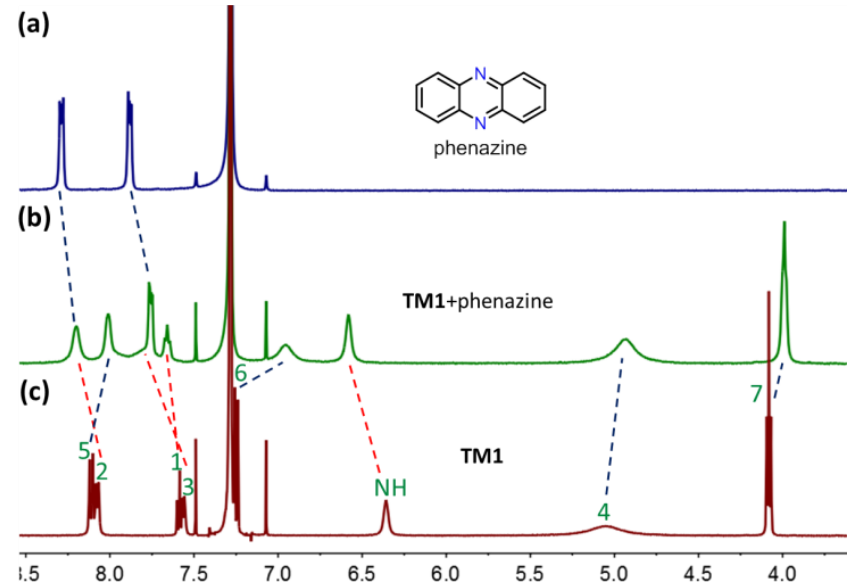

Figure 4 Partial ${ }^{1} \mathrm{H}$ NMR spectra (500 MHz, CDCl $, 298 \mathrm{~K}, 0.5 \mathrm{mM}$ ) of (a) phenazine, (c) TM1, and (b) their equimolar mixture.

To understand the high binding selectivity of TM1 to phenazine, molecular modelling was performed on the complex phenazine@TM1. As shown in Figure 5a, four hydrogen bonds $(\mathrm{H} \cdots \mathrm{N}$ distance, $2.40 \AA)$ between the two nitrogen atoms of phenazine and the four amide protons are formed. Phenazine is sandwiched between the two 2,6-dibutoxylnaphthalene sidewalls. Phenazine and the naphthalenes are within the distance (3.65 of $\pi-\pi$ interactions, and $\sigma-\pi$ interactions should also be involved. This arrangement is in line with the observation in ${ }^{1} \mathrm{H}$ NMR spectra. Therefore, $\mathrm{N}-\mathrm{H} \cdots \mathrm{N}$ hydrogen bonding, $\pi-\pi$ and $\sigma-\pi$ interactions should be the major driving force for the binding between $\mathrm{TM} 1$ and phenazine in $\mathrm{CDCl}_{3}$.

Theoretically, the binding mode between phenazine and TM1 should be satisfied by 9 as well. However, no obvious binding was 
detected between $\mathbf{9}$ and TM1. Electrostatic potential surface is helpful in explaining this high binding selectivity. As shown in Figure $5 b$, the electrostatic potential surfaces of 9 and phenazine are rather similar, but the negative charge regions on oxygen atoms of $\mathbf{9}$ are obviously smaller than those on nitrogen atoms of phenazine. The electrostatic potential surface in the cavity of TM1 is more complementary to the electrostatic potential surface of phenazine. However, this would not cause binding to 9 at all. We think the additional positive charge on the benzo rings of 9 results in severe repulsion with the amide protons of TM1, leading to the tomplete shutdown of the binding between TM1 and 9. This may

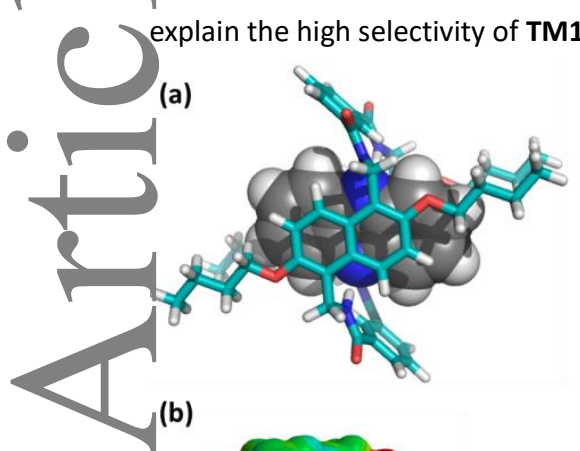

(b)

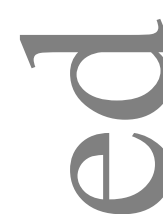

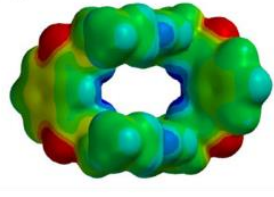

TM1

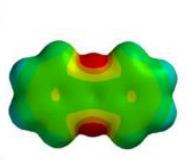

phenazine

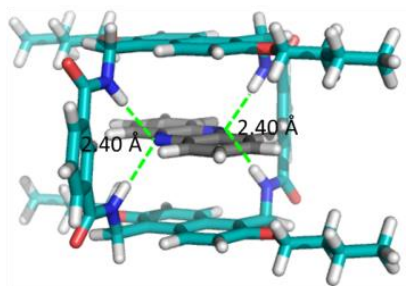

igure 5 (a) Energy-minimized structure of phenazine@TM1 at the level of Jeory of PM6 by using Spartan '14 (Wavefunction, Inc.); (b) Electrostatic potential surfaces of TM1, phenazine and 9

In addition, tetralactam macrocycle TM1 is fluorescent (1) pecause of the 2,6-dibutoxylnaphthalene sidewalls. The UV-Vis absorption spectrum was shown in Figure $6 a$, and the maximal peaks are located at 243, 283 and $350 \mathrm{~nm}$. The optimal excitation wavelength is at $350 \mathrm{~nm}$ with an emission peak at $378 \mathrm{~nm}$. The quantum yield of TM1 is ca. $9.0 \%$ in $\mathrm{CH}_{2} \mathrm{Cl}_{2}$. The fluorescent esponse of TM1 to phenazine was also investigated. As shown in Figure $6 \mathrm{~b}$, the addition of phenazine into the solution of TM1 causes significant quenching of its fluorescence. Therefore, TM1 may be used as a fluorescent sensor for phenazine in solution.
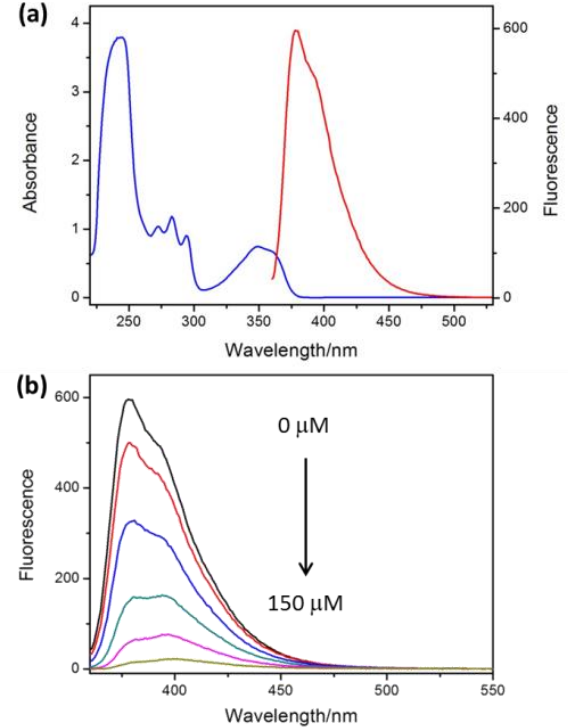

Figure 6 (a) Absorption spectrum (blue line) and fluorescence emission spectrum (red line) of TM1 in $\mathrm{CH}_{2} \mathrm{Cl}_{2}$; (b) fluorescence emission spectra of TM1 $(10 \mu \mathrm{M})$ upon addition of different concentrations of phenazine (0 $150 \mu \mathrm{M})$ in $\mathrm{CH}_{2} \mathrm{Cl}_{2}$.

\section{Conclusions}

In summary, we reported the synthesis and characterization of a new tetralactam macrocycle based on 2,6-dibutoxylnaphthalene. This macrocycle shows rather high binding selectivity to phenazine - a well-known secondary metabolite in bacteria and an emerging disinfection byproduct in drinking water. It was revealed that hydrogen bonding, $\pi-\pi$ and $\sigma-\pi$ interactions are the major driving forces for the binding, and perfect complementarity in electrostatic potential surfaces of the guest and the host determine the high binding selectivity. Furthermore, efficient fluorescent quenching of the macrocycle upon adding phenazine was observed. Therefore, the 2,6-dibutoxylnaphthalene-based tetralactam macrocycle may be used as a fluorescent sensor for phenazine. Although the binding and sensing was achieved in nonpolar solvent rather than water, phenazine may be extracted from water and is then detected in organic solvents. This is quite common for the detection of environmental contaminants in water. $^{33}$

\section{Experimental}

General method. All the reagents involved in this research were commercially available and used without further purification unless otherwise noted. Solvents were either employed as purchased or dried prior to use by standard laboratory procedures. NMR spectra were recorded on Bruker Avance-400 
(500) spectrometers. All chemical shifts are reported in ppm with residual solvents as the internal standards. Electrospray-ionization time-of-flight high-resolution mass spectrometry (ESI-TOF-HRMS) experiments were conducted on an applied biosystems Elite ESI-QqTOF mass spectrometry system. Fluorescence spectra were obtained on a Shimadzu RF-5301pc spectrometer. UV-vis absorption spectra were obtained on a Hitachi U-2600 UV-vis spectrophotometer. Absolute fluorescence quantum yields were recorded with Hamamatsu absolute FL quantum yield spectrometer C11347.

Synthetic Procedure of Macrocycle TM1: The solution of the 2,6-dibutoxylnaphthalene diamine $(0.66 \mathrm{~g}, 2.0 \mathrm{mmol}$; see Scheme 1) in $60 \mathrm{~mL}$ dry $\mathrm{CH}_{2} \mathrm{Cl}_{2}$ and the solution of isophthaloyl dichloride ( $0.40 \mathrm{~g}, 2.0 \mathrm{mmol})$ in dry $\mathrm{CH}_{2} \mathrm{Cl}_{2}(60 \mathrm{~mL})$ were added slowly through a syringe pump with two syringes to the solution of Hünig's base $(3.4 \mathrm{~mL}, 20.0 \mathrm{mmol})$ in $\mathrm{CH}_{2} \mathrm{Cl}_{2}(300 \mathrm{~mL})$ over a period of $10 \mathrm{~h}$ at room temperature. The resulting mixture was stirred for another $6 \mathrm{~h}$. Solvents were removed under vacuo, and the residue was dissolved in $\mathrm{CH}_{2} \mathrm{Cl}_{2}(50 \mathrm{~mL})$. The organic layer was washed with $10 \%$ aqueous $\mathrm{HCl}(50 \mathrm{~mL})$ followed by saturated aqueous $\mathrm{NaHCO}_{3}(100 \mathrm{~mL})$ and dried over $\mathrm{Na}_{2} \mathrm{SO}_{4}$. After removing the solvent, the residue was subjected to column chromatography $\left(\mathrm{SiO}_{2}, \mathrm{CH}_{3} \mathrm{OH} / \mathrm{CH}_{2} \mathrm{Cl}_{2}=1 / 100\right)$ to afford TM1 $(0.18 \mathrm{~g}, 20 \%)$ as a white solid.

\section{Supporting Information}

The supporting information for this article is available on the WWW under https://doi.org/10.1002/cjoc.2018xxxxx.

\section{Acknowledgement}

This research was financially supported by the National Natural Science Foundation of China (Nos. 21705075 and 21822104), the SZSTI (Nos. JCYJ20180504165810828 and KQJSCX 20170728162528382), the Shenzhen Nobel Prize Scientists Laboratory Project (C17213101), the Open Fund of State Key Laboratory of Chemo/Biosensing and Chemometrics of Hunan University (2017019), and the Academy of Finland (A.V. grant no. 314343) and the University of Jyväskylä. We thank SUSTech-MCPC for instrumental assistance.

\section{Reference}

[1] Turner, J.M.; Messenger, A.J. Occurrence, biochemistry and physiology of phenazine pigment production. Adv. Microb. Physiol. 1986, 27, 211-275.

[2] Shi, B.B.; Zhang, Y.M.; Wei, T.B.; Zhang, P.; Lin, Q.; Yao, H. Recognition of dihydrogen phosphate ions using the cadmium complex of 2-pyridine-1H-imidazo[4,5-b]-phenazine: utilization of the mechanism of twisted intramolecular charge transfer, long wavelength emission. New J. Chem. 2013, 37, 3737-3744.

[3] Gozalvez, C.; Zafra, J. L.; Saeki, A.; Melle-Franco, M.; Casado, J.; Mateo-Alonso, A. Charge transport modulation in pseudorotaxane 1D stacks of acene and azaacene derivatives. Chem. Sci. 2019, 10, 2743-2749.

[4] Gill, M.R.; Cecchin, D.; Walker, M.G.; Mulla, R.S.; Battaglia, G.; Smythe, C.; Thomas, J.A. Targeting the endoplasmic reticulum with a membrane-interactive luminescent ruthenium(II) polypyridyl complex. Chem. Sci. 2013, 4, 4512-4519.

[5] Zhou, W.J.; Boyd, J.M.; Qin, F.; Hrudey, S.E.; Li, X.F. Formation of nitrosodiphenylamine and two new $\mathrm{N}$-containing disinfection byproducts from chloramination of water containing diphenylamine. Environ. Sci. Technol. 2009, 43, 8443-8448.

[6] Zhou, W.; Lou, L.; Zhu, L.; Li, Z.; Zhu, L. Formation and cytotoxicity of a new disinfection by-product (DBP) phenazine by chloramination of water containing diphenylamine. J. Environ. Sci. 2012, 24, 1217-1224.

[7] McGuigan, C. F.; Li, X.-F. Cytotoxicity and genotoxicity of phenazine in two human cell lines. Toxicol. in Vitro 2014, 28, 607-615.

[8] Duriez, M. C.; Pigot, T.; Picard, C.; Cazaux, L.; Tisnes, P. Macrocyclic polyether tetralactams I: synthesis and cyclization studies. Tetrahedron 1992, 48, 4347-4358.

[9] Hunter, C. A. Molecular Recognition of p-Benzoquinone by a Macrocyclic Host. J. Chem. Soc., Chem. Commun. 1991, 749-751.

[10] Ottens-hildebrandt, S.; Meier, S.; Nieger, M.; Vögtle, F.; Weber, E. A new tetra-lactam host compound and its complexes with ethanol and dimethyl sulfoxide, Supramol. Chem. 1995, 5, 133-138.

[11] Szumna, A.; Jurczak, J. A New Macrocyclic Polylactam-Type Neutral Receptor for Anions-Structural Aspects of Anion Recognition. Eur. J. Org. Chem. 2001, 21, 4031-4039.

[12] Ke, C. F.; Destecroix, H.; Crump, M. P.; Davis, A. P. A simple and accessible synthetic lectin for glucose recognition and sensing Nat. Chem. 2012, 4, 718-723.

[13] Collins, C. G.; Peck, E. M.; Kramer, P. J.; Smith, B. D. Squaraine rotaxane shuttle as a ratiometric deep-red optical chloride sensor Chem. Sci. 2013, 4, 2557-2563.

[14] Johnston, A. G.; Leigh, D. A.; Pritchard, R. J.; Deegan, M. D. Facile Synthesis and Solid-state Structure of a Benzylic Amide [2]Catenane. Angew. Chem. Int. Ed. Engl. 1995, 34, 1209-1212.

[15] Affeld, A.; Hübner, G. M.; Seel, C.; Schalley, C. A. Rotaxane or Pseudorotaxane? Effects of Small Structural Variations on the Deslipping Kinetics of Rotaxanes with Stopper Groups of Intermediate Size. Eur. J. Org. Chem. 2001, 15, 2877-2890.

[16] Gassensmith, J. J.; Arunkumar, E.; Lorna Barr, L.; Baumes, J. M.; Noll, B. C.; Smith, B. D. Self-Assembly of Fluorescent Inclusion Complexes in Competitive Media Including the Interior of Living Cells. J. Am. Chem. Soc. 2007, 129, 15054-15060.

[17] Martinez-Cuezva, A.; Lopez-Leonardo, C.; Bautista, D.; Alajarin, M.; Berná, J. Stereocontrolled Synthesis of $\beta$-Lactams within [2]Rotaxanes: Showcasing the Chemical Consequences of the Mechanical Bond. J. Am. Chem. Soc. 2016, 138, 8726-8729.

[18] Liu, W.; Oliver, A. G.; Smith, B. D. Macrocyclic Receptor for Precious Gold, Platinum, or Palladium Co-ordination Complexes. J. Am. Chem. Soc. 2018, 140, 6810-6813.

[19] Adams, H.; Carver, F. J.; Hunter, C. A.; Osborne, N. J. Amide-aromatic hydrogen-bondsin host-guest recognition. Chem. Commun. 1996, 2529-2530.

[20] Hunter, C. A.; Sanders, J. K. M. The Nature of $\pi-\pi$ Interactions. J. Am Chem. Soc. 1990, 112, 5525-5534.

[21] Martinez, C. R.; Lverson, B. L. Rethinking the term "pi-stacking". Chem. Sci. 2012, 3, 2191-2201.

[22] Wang, L.-L.; Tu, Y.-K.; Yao, H.; Jiang, W. 2,3-Dibutoxylnaphthalenebased tetralactam macrocycles for recognizing precious metal chloride complexes. Beilstein J. Org. Chem. submitted.

[23] Huang, G.-B.; Valkonen, A.; Rissanen, K.; Jiang, W. Endo-Funtionalized Molecular Tubes: Selective Encapsulation of Neutral Molecules in Non-Polar Media. Chem. Commun. 2016, 52, 9078-9081.

[24] Yao, H.; Ke, H.; Zhang, X. B.; Pan, S.-J.; Li, M.-S.; Yang, L.-P.; Schreckenbach, G.; Jiang, W. Molecular Recognition of Hydrophilic Molecules in Water by Combining the Hydrophobic Effect with Hydrogen Bonding. J. Am. Chem. Soc. 2018, 140, 13466-13477. 
[25] Huang, G.-B.; Liu, W.-E.; Valkonen, A.; Yao, H.; Rissanen, K.; Jiang, W. Selective Recognition of Aromatic Hydrocarbons by Endo-Functionalized Molecular Tubes via $\mathrm{C} / \mathrm{N}-\mathrm{H} . . . \pi$ Interactions. Chin Chem. Lett. 2018, 29, 91-94.

[26] Huang, G.-B.; Wang, S.-H.; Ke, H.; Yang L.-P.; Jiang, W. Selective Recognition of Highly Hydrophilic Molecules in Water by Endo-Functionalized Molecular Tubes. J. Am. Chem. Soc. 2016, 138, 14550-14553.

[27] Wang, L.-L.; Chen, Z.; Liu, W.-E.; Ke, H.; Wang S.-H.; Jiang, W. Molecular Recognition and Chirality Sensing of Epoxides in Water Using Endo-Functionalized Molecular Tubes. J. Am. Chem. Soc. 2017, 139, 8436-8439.

[28] Bai, L.-M.; Zhou, H.; Liu, W.-E.; Chai, H. X.; Yang, L.-P.; Yan, W.; Zhang W.; Yang, H.-H.; Jiang, W. Fluorescent Monitoring on the Reaction Kinetics of Nonfluorescent Molecules Enabled by a Fluorescent Receptor. Chem. Commun. 2019, 55, 3128-3131.

29] Bai, L.-M.; Yao, H.; Yang, L.-P.; Zhang, W.; Jiang, W. Molecular Recognition and Fluorescent Sensing of Urethane in Water. Chin. Chem. Lett. 2019, 30, 881-884.

[30] Cui, J.-S.; Ba, Q.-K.; Ke, H.; Valkonen, A.; Rissanen, K.; Jiang, W.
Directional Shuttling of a Stimuli-Responsive Cone-Like Macrocycle on a Single-State Symmetric Dumbbell Axle. Angew. Chem. Int. Ed. 2018, 57, 7809-7814.

[31] Ma, Y.-L.; Ke, H.; Valkonen, A.; Rissanen, K.; Jiang, W. Achieving Strong Positive Cooperativity through Activating Weak Non-Covalent Interactions. Angew. Chem. Int. Ed. 2018, 57, 709-713.

[32] Ke, H.; Yang, L.-P.; Xie, M.; Chen, Z.; Yao, H.; Jiang, W. Shear-induced Assembly of a Transient yet Highly Stretchable Hydrogel Based on Pseudopolyrotaxanes. Nat. Chem. 2019, 11, 470-477.

[33] Song, D.; Zhang, S. Rapid Determination of 1,4-dioxane in Water by Solid-Phase Extraction and Gas Chromatography-Mass Spectrometry. J. Chromatogr., A 1997, 787, 283-287.

(The following will be filled in by the editorial staff)

Manuscript received: XXXX, 2019

Manuscript revised: XXXX, 2019

Manuscript accepted: XXXX, 2019

Accepted manuscript online: XXXX, 2019

Version of record online: XXXX, 2019 


\section{Entry for the Table of Contents}

Page No.

Title

Selective Recognition of Phenazine by 2,6-Dibutoxylnaphthalene-Based Tetralactam Macrocycle
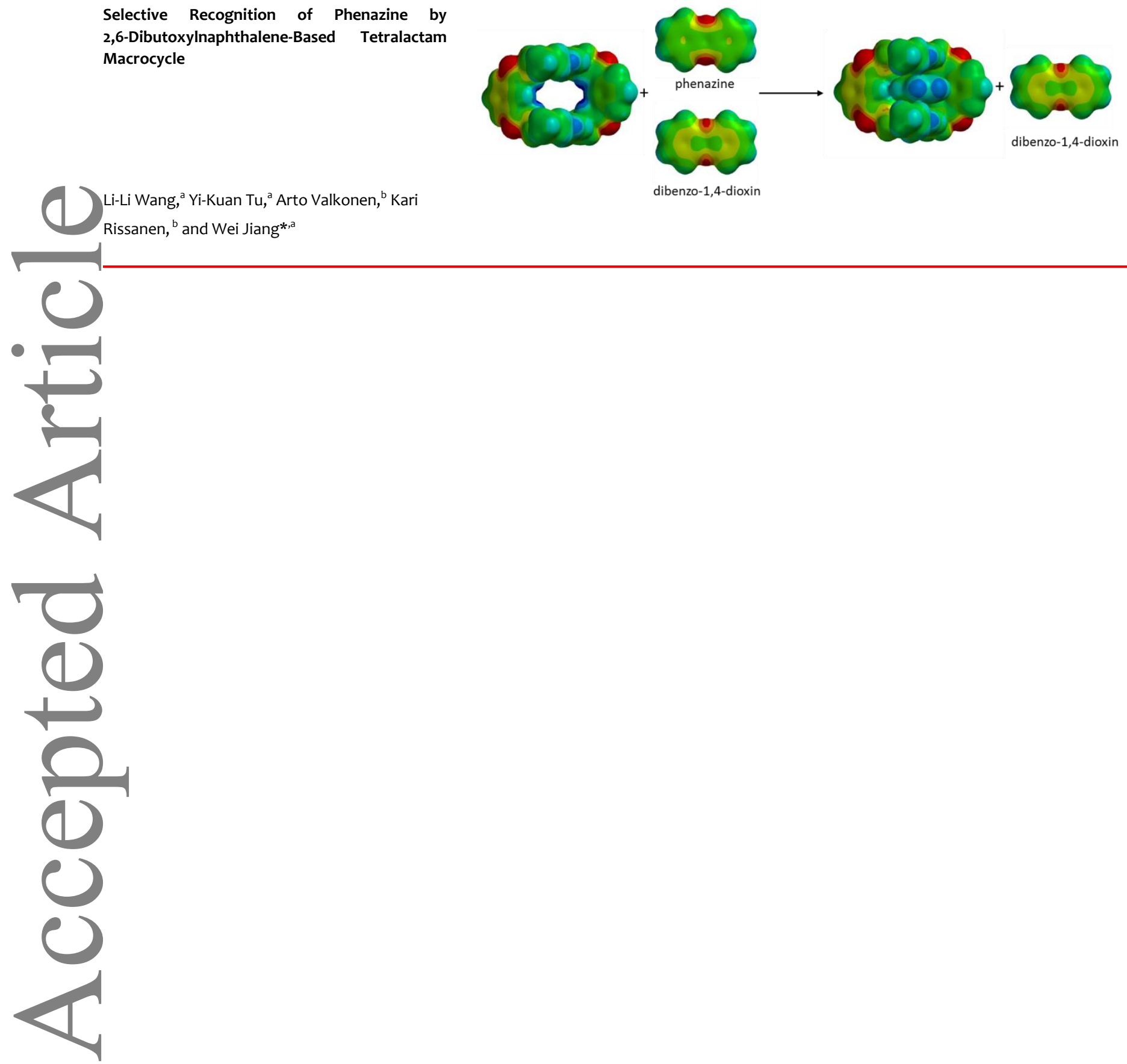

${ }^{a}$ Department, Institution, Address 1 E-mail:

${ }^{b}$ Department, Institution, Address 2 E-mail:
${ }^{c}$ Department, Institution, Address 3

E-mail: 